\title{
BUILDING ERECTION ASSIST SYSTEM APPLIED FOR ACTIVITY CHECKING METHOD
}

\author{
Yoshihisa Masamura \\ Kajima Technical Research Institute \\ 2-19-1 Tobitakyu Chofu-shi, Tokyo, Japan \\ masamura@kajima.com
}

\begin{abstract}
Already, authors provided the method (activity checking method) which does planning validity checking whether the execution of the activity will be possible or not used work data and component data, and construction progress checking used completed wok data. Assist functions of this method are used for construction from planning to progress controlling. In this study, we developed the building erection assist system used activity checking method in order to show the assist function of this method. Also, we cleared that the realization of activity checking method means computerize of planning and progress controlling. The development of actual tool assisting planning and progress controlling of build erection based on this system, is the subject for a future study.
\end{abstract}

\section{KEYWORDS}

Building Erection, Assist Method, Activity Checking Method, Information Technology

\section{INTRODUCTION}

There are many studies for methods assisting the planning and progress controlling of construction. The assist methods of schedule controlling being a part of planning and progress controlling, are widely used through commercial tools having those assist methods (eg. critical pass method). However, in order to assist whole planning and progress controlling of construction, the assist method using position/shape data of heavy equipments, temporary facilities and components, is also necessary. The field of the study of this paper is the planning and progress controlling assist method which uses building model having position /shape data of components and have automatic planning function or optimization function.

As researches related to whole part of construction planning assist method, there are studies applied for artificial intelligence. Fischer/Aalami ${ }^{1)}$ developed the method which automatically generates process model (activity sequence model) used three dimensional building model and work-specimen precedence models.

As researches about work space allocation, there are studies applied for 4-diemnsion (time/space) model. Akinci et $\mathrm{al}^{2)}$ reported automatic generation of work space volume and duration by simulation used 4-diemnsion product model and work space data. Guo ${ }^{3)}$ developed decision assist tool to solve space conflict required temporary work spaces in site plane. This tool uses linking scheduling software. The researches of optimization method related to lift planning continue more than ten years. Zhang et $\mathrm{al}^{4)}$ studied optimization method of tower cranes planning. Location criteria are balanced workload, minimum likelihood of conflicts with each other, and high efficiency of operations. Experimental results indicate that the computerized model performs satisfactorily. AI-Hussen et $\mathrm{al}^{5)}$ developed lift planning assist method having optimum algorithm of mobile crane location and specification. This algorithm use geometrics, three dimensional length and lift capacity, and is similar to traditional lift planning heuristics. 
A variety of assist methods are proposed as above-mentioned. However, there are no assist methods which are widely used, as method assisting whole planning and progress controlling. The other hand, authors provided activity checking method $^{6)}$ supporting construction planning. The characteristics of this method are the simple concept and the wide range of the application. The previous paper ${ }^{6)}$ told the abstract of activity checking method, but did not explain the contents of checking items (checking rules) of activity checking method. This paper shows the contents of checking items (checking rules) through the content of the building erection assist system applied for activity checking method.

\section{OBJECT}

The purpose of this paper is to show the contents of checking items of activity checking method and verified results of checking items by the system applied for activity checking method. The abstract of activity checking method are showed in chapter 3 and the contents of checking items are showed in chapter 4 . The characteristics of activity checking method are cleared by the comparison among the other assist methods in chapter 5 .

\section{ACTIVITY CHECKING METHOD}

\subsection{The Definition of Activity Checking}

The basic unit of work is activity. The evaluation of activities is necessary when planning and progress controlling is executed. The checking is the evaluation dividing activities two kinds whether success or failure. The checking using computer is possible if checking data and checking rules are set in computer.

In this paper, authors define activity checking as logical matching check among data related to an activity by computer.

The checking whether an activity will be possible to execute or not, is effective in planning work. Also, the checking whether an activity has been done along schedule plan or not, is useful in progress controlling work. The role of activity checking is not substitute of man's brainwork but back-up of man's brainwork.

\subsection{Abstract of Activity Checking Method}

The concept of activity checking method is as follows. Under the condition that data related to activity is taken in computer, the automatic check of activity execution-possibility and activity in-schedule is possible by checking rules (computer algorithm). Also, the simple automatic setting of a checking condition (a construction parameter) is possible.

The activity checking method is the generic name of checking rules, which are indispensable mechanisms to realize activity checking. Authors call the group of classified checking rules checking item. Table1. shows checking items of activity checking method. In table1., milestone checking is the check comparing activity time (planning and completed) and milestone time. Progress checking is the check comparing an activity's (or a component's) planning time and completed time. The other six checking items are the check of activity execution-possibility. For all checking items, checks are executed about a component or an activity.

\section{CONTENTS OF SYSTEM}

\subsection{Abstract of Development}

We developed the building erection assist system for planning and schedule controlling based on the concept of activity checking method. Work specimens dealing with this system are erection work, erection conditioning work, temporary component removed work, bolt fasten work, welding work and ultrasonic examination work. Component specimens dealing with this system are column, beam, auxiliary component (brace etc.), temporary component and conjunction component. The conjunction component is virtual component, and has number of bolts and length of welding in each component. The main development of this system is checking rule's part, and input/output interface part is limited in level to be able to validate checking rule's functions. AutoCAD software was used to display computer screen of building skeleton.

In this system, the stocks checking and structure checking within checking items showed table1. are omitted. 
Authors have simulated building erection applied for this system under actual erection schedule. As this simulation result, the checks of each activity and each component about all work specimens of this building erection have succeeded.

\subsection{Main Functions}

Figure 1 shows the main functions of the system. Rectangular frames of figure1. show mainfunctions and arrows between rectangular framesshow the flow of use. Figure 2. shows the screenof data manipulation and display of the main system functions except for "Erection component model generation" and "Preparatory disposal".

The screen of figure 2. consists of the schedule display part used bar chart, 2,3 dimensional display part of erection component model and detailed data display part of an activity. As the time of activity, working day which is accumulative work day from construction start and calendar day are used.

\section{Table1 Checking Items of Activity Checking Method}

\begin{tabular}{|l|l|}
\hline Checking item & \multicolumn{1}{|c|}{ Function } \\
\hline Milestone checking & $\begin{array}{l}\text { Dose the activity time } \\
\text { exceed to milestone time? }\end{array}$ \\
\hline Progress checking & $\begin{array}{l}\text { Comparison of planning } \\
\text { time and completed time }\end{array}$ \\
\hline $\begin{array}{l}\text { Component precedence } \\
\text { checking }\end{array}$ & $\begin{array}{l}\text { In component-work start } \\
\text { time, are all predecessors of } \\
\text { this component-work } \\
\text { completed ? }\end{array}$ \\
\hline $\begin{array}{l}\text { Equipment specification } \\
\text { limits checking }\end{array}$ & $\begin{array}{l}\text { Checking the specification } \\
\text { limit like a lift capacity of } \\
\text { crane }\end{array}$ \\
\hline $\begin{array}{l}\text { Space interference } \\
\text { checking }\end{array}$ & $\begin{array}{l}\text { Space interference } \\
\text { checking under } \\
\text { set-up/material } \\
\text { traveling/works }\end{array}$ \\
\hline Activity time checking & $\begin{array}{l}\text { Is the duration of work } \\
\text { within activity start/end } \\
\text { time? }\end{array}$ \\
\hline Stocks checking & $\begin{array}{l}\text { Checking of the spare } \\
\text { amount of temporary } \\
\text { facilities stocks }\end{array}$ \\
\hline Structure checking & $\begin{array}{l}\text { Strength and deformation } \\
\text { checking after setting up of } \\
\text { components }\end{array}$ \\
\hline
\end{tabular}

The functions related activity checking method within the main function of the system are "Activity generation and checking on each work specimen", "Crane data input and erection checking" and "Activity checking for all work specimens, Input/checking of completed work data".

In the stage of activity generation and checking on each work specimen, users primarily generate no component's activities at bar chart display part (fig.2), secondary select components allotted each activity at display part (fig.2) of erection component model. A few checking items are automatically executed in activity generation. If the result of checking is failure, error sign is showed on failed activities of bar chart. The reasons of the failure of the checking are showed at detailed data display part (fig.2) by selecting (click) failed an activity.

In the stage of crane data input and erection checking, users execute data input and checking for erection work and temporary component removed work. The checking items of erection checking are equipment specification limits checking and space interference checking. The failed results of erection checking instantaneously display on computer screen. In the stage of activity checking for all work specimens and input/checking of completed work data, users study planning and progress controlling by progress checking and component precedence checking related to work specimens precedence.

The main functions of the system not to be related directory with activity checking method are "Erection component model generation", "Preparatory disposal" and "Animation of build erection etc. " ( in figure1.). For erection component model generation and preparatory disposal, authors used the software modules of erection planning system ${ }^{6}$. There are two methods generating erection component model. One is manual input used modeler. The other is automatic input from three dimensional CAD data.

In preparatory disposal, there are component weight calculation from component volume, separation of column segment, adding bracket of beam part to column segment, and modification of component weight. In this software module, conjunction components are automatically generated at every conjunction positions. 
The function of the animation of building erection is easily realized because activities have both time data and component position/shape data.

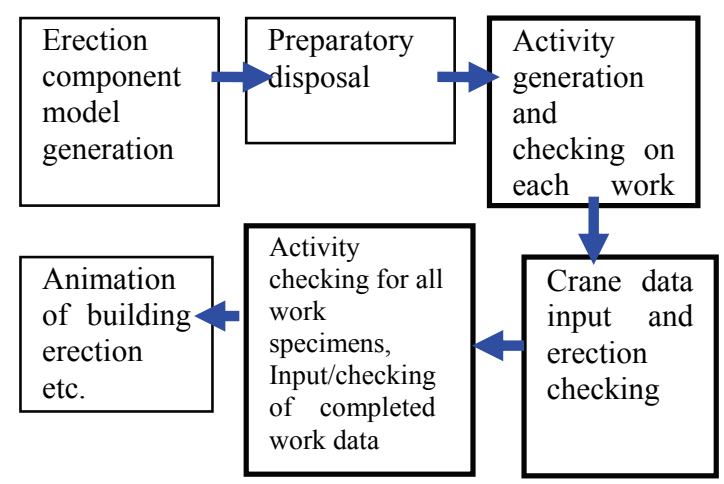

Figure 1 The Main Functions of the System

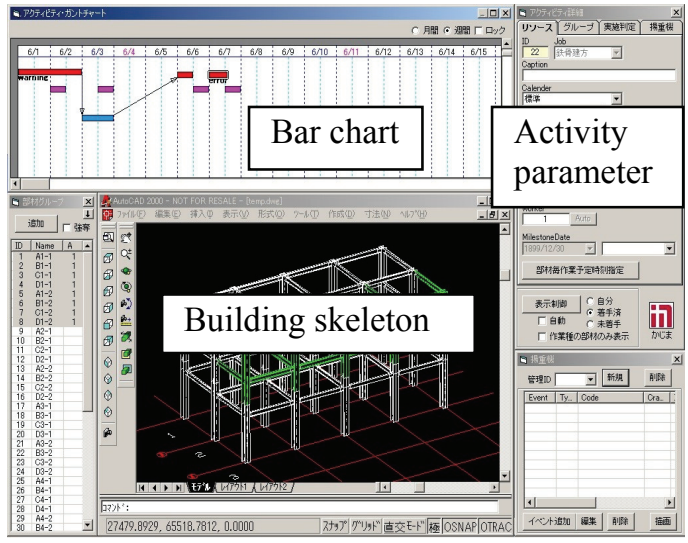

Figure 2 The Screen Display of the Several System Functions

\subsection{Contents of Checking Items (Checking Rules)}

\subsubsection{Component preceding checking}

The component preceding checking is success if the checks of all components including the activity could succeed. Component preceding checking on each work specimen judge every component as follows:

(1) About components of the activity, is the work of predecessor work specimen completed?

(2) Are there no problems in construction state of components supporting object's component?
For example of (1) case, the component preceding checking of the activity of ultrasonic examination work do not succeed if the welding works of all components in the activity could not be completed.

For erection work in (2) case, the component preceding checking about all work specimens ( or several work specimens ) is different from the checking about only erection work specimen. For the example of column erection work, the component preceding checking about all work specimens judges whether the bolt fasten work and welding work of the conjunction components under the column are accomplished. However, in the component preceding checking about only erection work, the check succeeds if the erection work of the bellow column could be completed. Figure3. shows the failed example of the component preceding checking about only erection work.
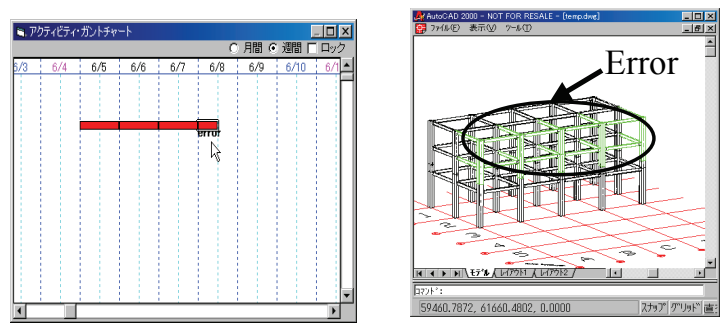

Figure 3 The failed example of component precedence checking

For another example, the component preceding checking of the bolt fasten work and welding work judges whether the erection works of all components linked the conjunction component are accomplished.

\subsubsection{Equipment specification limits checking and space interference checking}

The equipment specification limits checking and space interference checking are success if the checks of all components including the activity could succeed. The equipment specification limits checking is replaced with crane load-capacity checking because the object of the system is building erection.

The detailed items of crane load-capacity checking are work distance checking and lift capacity checking. The detailed items of space interference checking are lift height checking and contact 
checking which calculates whether crane boom contacts built components or not.

The contact checking criteria is the shortest distance between central axis of crane beam and central axis of built components. In the case of the shortest distance less than two meter, contact checking is failure. The value of the contact checking criteria can be modified on computer screen. The crane is located at the position linked to an activity or several activities.

\subsubsection{Activity Time Checking}

The activity time checking is executed to make a comparison between activity duration time set directly and activity calculation time calculated from amount of work of the activity. The activity time checking succeeds if the activity calculation time could be less than the activity duration time.

Figure 4. shows the success example of activity time checking on the activity generation and checking of erection work. For this example, all erection components in display part (fig.4) are allotted to one day activity, which has 8 hours as activity duration time. The activity calculation time, $5 \mathrm{~h} 27 \mathrm{~m}$ is simultaneously displayed when erection components are allotted to the activity. The error sign is not displayed because the activity calculation time is less than the activity duration time. If the activity calculation time could be more than the activity duration time, the error sign is displayed on the bar chart and the calculation time column on the activity parameter display part is turned to red color.

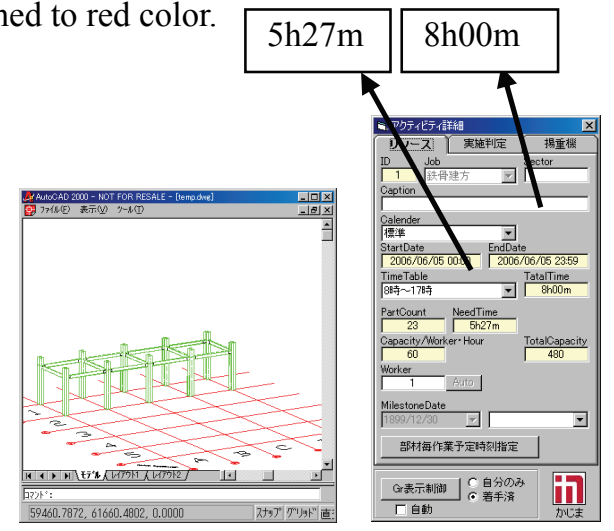

Figure 4 The success example of activity time checking

\subsubsection{Milestone checking and progress checking}

The milestone checking and progress checking are executed on each activity. Under designating milestone time to arbitrary activity, milestone checking judges to make a comparison between the activity time and the milestone time. The designated conditions of milestone time are finish more early designating time, start more early designating time, finish more late designating time, start more late designating time and so on. The milestone checking is used both planning and progress controlling because activity time has planning time and completed time. (This system has not the function of the progress checking.)

\section{DISCUSSION}

\subsection{The Positioning of Activity Checking Method}

As the general methods applying for the assist of planning, there are optimization method and critical path method. Table 2. shows the function of assist methods( the general method adding activity checking method ) applying to planning.

From table 2. it is cleared that assist functions of these methods are different. Also, computer models of these methods are different. Therefore, each method is independent of the other methods. For assist functions of construction planning, activity checking method is complementary relation to optimization method and critical path method. Activity checking method is the general planning assist method having assist functions which are different from optimization method and critical path method, and is not only the planning assist method but also the assist method of progress controlling.

\subsection{The Significance of Activity Checking Method}

By using activity checking method, the bad points of planning and progress controlling work are accurately showed. It is considered that the usefulness of activity checking method will become motivation to promote realizing this method.

The realization of the assist tool combined a variety of assist methods and activity checking method, means the transfer of planning and progress controlling work from paper work to computer work. Activity checking method will be expected to become one of future computer assist methods. 
Table 2 The Function of Assist Methods Applying to Planning

\begin{tabular}{|l|l|}
\hline Assist method & \multicolumn{1}{|c|}{ Function } \\
\hline $\begin{array}{l}\text { Activity } \\
\text { checking } \\
\text { method }\end{array}$ & $\begin{array}{l}\text { Checking of activity } \\
\text { execution-possibility and } \\
\text { activity obeying construction } \\
\text { period limit, Construction } \\
\text { parameter can be modified by } \\
\text { using checking results }\end{array}$ \\
\hline $\begin{array}{l}\text { Optimization } \\
\text { method }\end{array}$ & $\begin{array}{l}\text { Derivation of solutions to } \\
\text { minimize objective variable in } \\
\text { objective function }\end{array}$ \\
\hline $\begin{array}{l}\text { Critical Path } \\
\text { Method }\end{array}$ & $\begin{array}{l}\text { Calculation of critical path, } \\
\text { Calculation of earliest } \\
\text { start/finish time, latest } \\
\text { start/finish time and total/free } \\
\text { float }\end{array}$ \\
\hline
\end{tabular}

\section{SUMMARY}

The result of this study is that the contents and characteristics of activity checking method are cleared through the development of the building erection assist system applied for this method. For assist functions of construction planning, activity checking method is complementary relation to optimization method and critical path method. The realization of activity checking method means computerize of planning and progress controlling. The development of actual assist tool based on this system is the subject for a future study.

\section{REFERENCES}

[1] Martin Fischer, Florian Aalami : Schduling with Computer-Interpretable Construction Method Models, J. of Construction Engineering and Management, ASCE, DEC. 1996, P.337-347

[2] Burcu Akinci, Martin Fischer, John Kunz, Ray Levitt : Representing Work Spaces Generically in Construction Method Models" J. of Construction Engineering and Management, ASCE , JUL./AUG. 2002， P.296-305

[3] Sy-jyeGuo : Identification and Resolution of Work Space Conflicts in Building Construction, J. of Construction Engineering and Management, ASCE, JUL./AUG. 2002, P.287-295

[4] P. Zhang, E. C. Harris, P. O. Olomolaive, G. D. Holt: Location Optimization For a Group of Tower Cranes,J. of Construction Engineering and Management, ASCE, MAR./APR. 1999, P.115-122

[5] AI-Hussen,M., Alkass,S.,and Moselhi,O.: Optimization Algorithm for Selection and on Site Location of Mobile Cranes, J. of Construction Engineering and Management, ASCE , MAY 2005, P.579-590

[6] Yoshihisa Masamura: Construction Planning Assist Method used Construction Model, 23rd ISARC, 2006, P.884-889 